\title{
Erectile Dysfunction in Chronic Hemodialysis Patients in Dakar: a Cross- Sectional Study in 2012
}

\author{
Elhadj Fary Ka ${ }^{1}$; Sidy Mohamed Seck ${ }^{2, *}$; Mouhamadou Moustapha Cisse ${ }^{1}$; Ahmeth Tall Ould \\ Lemraboot ${ }^{1}$; Maria Faye ${ }^{1}$; Abdou Niang ${ }^{1}$; Boucar Diouf ${ }^{1}$ \\ ${ }^{1}$ Nephrology Department, Faculty of Medicine, University Cheikh Anta Diop, Dakar, Senegal \\ 2 Internal Medicine and Nephrology Department, Faculty of Health Sciences, University Gaston Berger, Saint-Louis, Senegal \\ *Corresponding author: Seck Sidy Mohamed, Internal Medicine and Nephrology Department, Faculty of Health Sciences, University Gaston Berger, Saint-Louis, Senegal. Tel/Fax: +221- \\ 339619974, E-mail: sidy-mohamed.seck@ugb.edu.sn
}

Received: July 11, 2014; Accepted: August 30, 2014

\begin{abstract}
Background: Patients with chronic kidney disease (CKD) experience multiple complications including erectile dysfunction (ED). It involves more than $50 \%$ of patients on dialysis or transplant. In Africa, the true extent of ED in CKD is unknown although some studies have been done in this regard.

Objectives: This study aimed to determine the prevalence and identify risk factors of ED in patients on hemodialysis.

Patients and Methods: This cross-sectional multicenter study was conducted from January 2, 2012 through April 30, 2012 in four hemodialysis centers in Dakar. We included all patients on chronic hemodialysis who aged $\geq 18$ years old and freely consented to participate in the study. Sociodemographic, clinical, and hemodialysis data were collected through a questionnaire. Erectile function was assessed by a short version of International Index of Erectile Function (IIEF-5).

Results: Among a target of 80 patients, 73 met the inclusion criteria and were included in this study. Mean dialysis vintage was 27.3 months (range, 1-156). Their mean age was $53.81 \pm 12.52$ years, with a higher proportion of age group of 50 to 69 years old. Fifty-six patients were married (37 monogamous and 19 polygamous) and six were singles. Overall prevalence of ED was $84.9 \%$ and it was severe in 14 patients (19.2\%). Hypertension and diabetes were the most frequent etiologies and antihypertensive treatment was used in $95.5 \%$. The main factors associated with ED were age $>50$ years old and polygamy.

Conclusions: ED is a common problem among patients on hemodialysis in Dakar with a high prevalence. Aging and diabetes represent most common causes. More efforts are needed for its early detection, prevention, and multidisciplinary management.
\end{abstract}

Keywords:Hemodialysis; Erectile Dysfunction; Epidemiology

\section{Background}

Patients with chronic kidney disease (CKD) experience multiple complications including sexual dysfunction. Erectile dysfunction (ED) is defined as the inability to achieve or maintain an erection sufficient for a satisfactory sexual intercourse (1). The severity of ED is directly correlated to the severity of CKD (2). In Africa, the true extent of ED in patients on hemodialysis remains unclear because of the taboos that surround the disease $(3,4)$. A previous study in the hemodialysis unit in Dakar found a prevalence rate of $81.4 \%$ (5).

\section{Objectives}

This study aimed to determine the current prevalence of ED, identify risk factors, assess the psychosocial effects, and evaluate the quality of the management of ED.

\section{Patients and Methods}

We conducted a cross-sectional descriptive multicenter study in four hemodialysis centers in the Dakar region from January 2, 2012 through April 30, 2012. All patients on chronic hemodialysis who were older than 18 years and deliberately consented to respond to questionnaire items were included. Erectile function was assessed by the short version of International Index of Erectile Function (IIEF-5) in French language, which was already validated in patients on hemodialysis. The questionnaire consisted of five items and each item was scored from one (not sure) to five (very safe). Score $<26$ points was consistent with ED.

In patients with ED, four grades of severity were defined as follows: mild (score, 17-21); light (score, 12-16); moderate (score, 8-11); and severe (score, 5-7)

Collected sociodemographic data included age, sex, and marital status (single, monogamous, or polygamous). Data on dialysis parameters (dialysis vintage, type of dialysis, and number of hemodialysis hours per week), the psychosocial effects, and the different treat-

Copyright ( 2014 , Nephrology and Urology Research Center. This is an open-access article distributed under the terms of the Creative Commons Attribution-NonCommercial 4.0 International License (http://creativecommons.org/licenses/by-nc/4.0/) which permits copy and redistribute the material just in noncommercial usages, provided the original work is properly cited. 
Ka EF et al.

ments were collected. The collected data were entered into Sphinx Plus2 Lexica Edition. Statistical analyses were performed with SPSS 13.0 (SPSS Inc., Chicago, IL, USA). The Chi square test was used for comparison of proportions and a $P$ value $<0.05$ was considered as statistically significant.

\section{Results}

From an initial target of 80 patients, 73 were included in the study. Among them, 62 presented ED according to their IEEF scores (prevalence of 84.9\%). Among those who had ED, 57 were on hemodialysis and five on peritoneal dialysis. The mean age was $53.81 \pm 12.52$ years and most of the patients who were affected by ED problems aged 50 years (see Figure 1). Fifty-six patients (90.2\%) were married ( 37 monogamous and 19 polygamous) and six were singles. The mean dialysis vintage was 27.3 months (range, 1-156). Periodicity of dialysis treatment was variable: thrice a week (51\%), twice a week (45.5\%), and once a week (3.5\%). The majority of patients presented with light to moderate ED while 14 (19.2\%) had severe dysfunction (Figure 2). Hypertension and diabetes were the two leading causes of initial nephropathy, which were found respectively in $59.6 \%$ and $21 \%$ of cases (see Figure 3). The associated comorbidities were consecutively hypertension (34\%), decompensated heart disease (21\%), and chronic viral hepatitis with hepatitis virus B (6.4\%) and C (3.2\%). Almost all patients (95.5\%) took antihypertensive drugs, which were mainly angiotensinconverting enzyme inhibitors (64.5\%), calcium channel blockers (59.6\%), diuretics (45.2\%), and beta-blockers (27.4\%). Only $5 \%$ of cases were taking erythropoietin. Other disorders such as sexual desire disorders (55\%), abnormal ejaculation (54\%), and disorders of orgasm or sexual satisfaction (44\%) were highlighted too. A specialized consultation was held for $26 \%$ of the patients with ED. Only $35.5 \%$ of patients were receiving treatment to improve their sexual function through taking sildenafil (24.2\%) or herbal medicine (11.3\%). Psychological consequences of ED in patients were dominated as anxiety (45.5\%), fear of failure (22.5\%), and insomnia (16\%). The majority of patients (61\%) received good understanding and psychological support from their partners. However, other reactions such as ignorance (13\%), anger (6.4\%), and resignation (4.8\%) were also reported. After bivariate analysis, only age $>50$ years and polygamy were significantly correlated with the risk of developing ED. Other factors such as the causal nephropathy, comorbidities, duration on dialysis, and the dialysis technique had no statistically significant association with ED (P value $>0.05$ )

\section{Discussion}

ED is a common disease with the prevalence ranging from $20 \%$ to $45 \%$ in general population. The incidence is even higher in patients on chronic dialysis due to specific

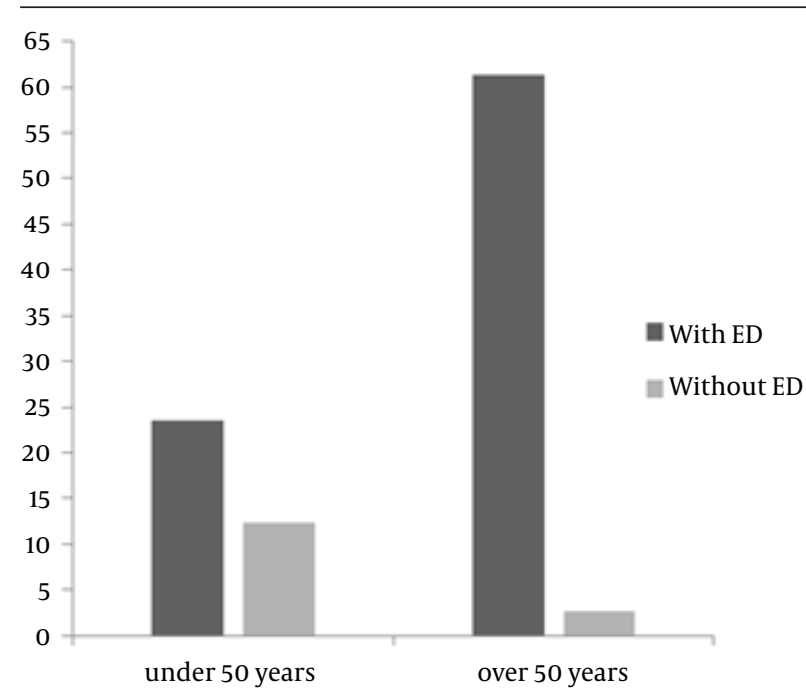

Figure 1. Distribution of Patients With Erectile Dysfunction According to Age

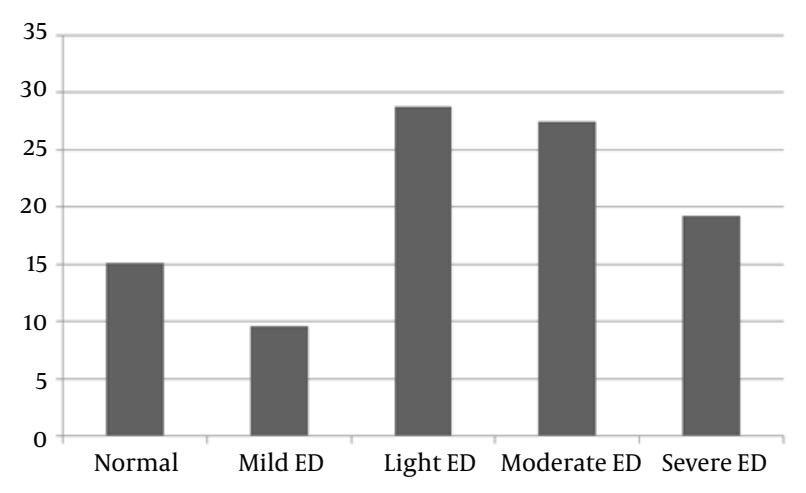

Figure 2. Distribution of Patients According to the Erectile Dysfunction

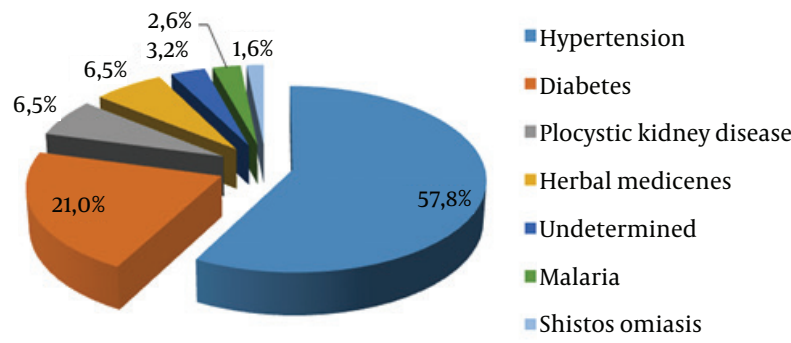

Figure 3. Causes of Renal Disease in Patients With Erectile Dysfunction

risk factors such as uremic toxins, anemia, mineral and bone disorders, and antihypertensive drugs adverse effects. In this study, $84.9 \%$ of patients presented ED. These results are similar to previous data reported by Seck et al. and Nassir et al. who found respectively preva- 
Ka EF et al.

lence of $81.4 \%$ in Senegal (5) and 83\% in Saudi Arabia (6). Lower prevalence of ED has been reported in patients on dialysis living in Spain (7), Brazil (8), and Netherlands (9) (respectively 60\%, 54.9\%, and 69\%). CIGOP in 1981 showed that more than $50 \%$ of male patients with CKD showed erectile dysfunction (10) The mild and moderate grades of $\mathrm{ED}$, with a prevalence of respectively $28.8 \%$ and $27.4 \%$, were the most represented severities in our patients. Only $19.2 \%$ of patients had severe form of ED which was in contrary to previous studies in Turkey (63\%) (11), Saudi Arabia (71\%) (6), and USA (12). The mean age was 52.8 years old, while Seck et al. had objectified an average age of 57.7 years (5). Sixty-one percent (61.4\%) patients aged 50 years and older had a ED ( $41 \%$ moderate and $20.4 \%$ against severe forms of mild and less light) against only $23.6 \%$ in less than 50 years whose $20.5 \%$ had mild and less mild and 3\% moderate and severe forms. Arslan et al. reported $86 \%$ of ED cases in patients over 50 years against $74.5 \%$ in patients aged less than 50 years (13). Rosas reported 90\% of ED in patients older than 50 years and $63 \%$ in patients less than 50 years (12). Most of our patients were married ( $89 \%$ with $29.2 \%$ being polygamous and $70.8 \%$ monogamous) and the rate of ED was higher among married (76.7\%) than unmarried (8.2\%) without any correlation between the ED and marital status. This lack of association was noted in almost all series (14-16). In our study, there was a statistically significant link between polygamy and ED. These results were similar to those reported by Diao et al. who showed that the severity of ED in the general population increased with the number of wives (17). No significant association between the duration on dialysis and DE was observed in our patients $(P=0.07)$. Seck et al. found the same results (5). Kleinclauss et al. concluded that hemodialysis vintage was a risk factor for ED through arteriopathy that worsens over time $(2,18)$. Conversely, Messina et al., Neto, and Naya et al. demonstrated that hemodialysis was not associated with $\operatorname{ED}(8,14,19)$. As in many studies (20-22), no association between ED and the mode of dialysis was noted in our patients and this was due to the small number of patients with PD (6.8\%). In China, Kwan et al. showed the negative effect of CAPD on the sexual life marked by a significant decrease in the frequency of sexual activity, libido, and sexual satisfaction among couples (23) renal failure patients. Fear of pulling PD catheters was one the main reason reported by most of couples (23).

In our study, there was no correlation between the underlying cause of CKD and ED, which was similar to the study of Nassir et al. (6). However, Cerqueira et al. and Miyata et al. found a significant association between ED and diabetes with respective p-values of 0.05 and $0.04(18,24)$. Thus, according to many writers, these pathologies are involved in the development of $\operatorname{ED}(7,20,25)$. Chronic liver disease related to hepatitis virus $\mathrm{B}$ or $\mathrm{C}$ and heart failure, which are described as potentiating factors of sexual dysfunction in patients on dialysis $(9,19,20)$, were objec- tified in one-third of our patients with $95.5 \%$ of them presenting ED. Several widely prescribed therapeutic classes, including $\beta$-blockers and diuretics, have been implicated in the onset of ED in patients on dialysis $(16,20,21)$. However, the most widely used classes of antihypertensive drugs in our study were angiotensin-converting enzyme inhibitors, calcium channel blockers, diuretics, and betablockers but no significant association between drug intake and the development of DE was objectified. ESA, used in $22 \%$ of our patients for the correction of chronic anemia, had a positive effect on the quality of sexual and erectile function. Other disorders such as sexual desire disorders, abnormal ejaculation, abnormal orgasm, or lack of sexual satisfaction were identified in $72 \%$ of cases. Only 35\% of patients were receiving treatment for ED. Sildenafil (24.2\%), as prescription or self-medication, and traditional medicines (ginseng plants and others) (11.3\%) were the most used drugs; on contrary, Neto et al. (19) showed that $90.4 \%$ of its population never had treatment for ED while $90 \%$ wanted a treatment. Finally, origins of ED appear as multifactorial, involving organic and psychologic disorders $(16,20,21)$. Our patients were exposed to psychologic factors such as stress (24\%), anxiety (21\%), panic (16\%), insomnia (16\%), and fear of failure (16\%). In the study by Fernandes et al. patients with ED had depression that could be associated with decrease in libido as well as self-esteem and a reluctance to seek pleasurable activities (26). According to other authors, ED might result in aggression, anger, shame, bitterness, isolation, anxiety, depression (27). This study showed that ED is a common problem among patients on hemodialysis in Dakar. It is a public health problem because its prevalence is $80 \%$ after the second year of hemodialysis and the mean age of patients is 50 years. It is frequently encountered in patients with diabetes and hypertension. Its clinical presentation is variable with ejaculatory dysfunction and decreased libido being the dominant features. Treatment should provide medical and psychologic support. Nephrologist and dialysis nurses should be more aware of the disorder for its early detection, prevention, and correct management that could improve patients' quality of life.

\section{Acknowledgements}

Authors would like to thanks all paramedical staff of Aristide Le Dantec Dialysis Unit for their technical assistance and patients for their participation in this study.

\section{Authors' Contributions}

Elhadj Fary Ka: design, data collection, statistical analysis, and writing the manuscript. Sidy M Seck: design, statistical analysis, and writing the manuscript. M. M. Cisse: study design, data collection, and drafting the manuscript draft. A.OL. Tall: data collection and drafting the manuscript. M. Faye: data collection and drafting the manuscript. A. Niang: data collection and manuscript review. B. Diouf: study design and manuscript review. 


\section{References}

1. Rosen RC, Cappelleri JC, Smith MD, Lipsky J, Pena BM. Development and evaluation of an abridged, 5-item version of the International Index of Erectile Function (IIEF-5) as a diagnostic tool for erectile dysfunction. Int J Impot Res.1999;11(6):319-26.

2. Kleinclauss F, Kleinclauss C, Bittard H. [Erectile dysfunction in renal failure patients and renal transplant recipients]. Prog Urol. 2005;15(3):447-55.

3. Ali ME, Abdel-Hafez HZ, Mahran AM, Mohamed HZ, Mohamed ER, El-Shazly AM, et al. Erectile dysfunction in chronic renal failure patients undergoing hemodialysis in Egypt. Int J Impot Res. 2005;17(2):180-5.

4. Zamd M, Farh M, Hbid O, Zabari M, Benghanem Gharbi M, Ramdani B, et al. [Sexual dysfunction among 78 Moroccan male hemodialysis patients: clinical and endocrine study]. Ann Endocrinol (Paris). 2004;65(3):194-200.

5. Seck SM, Dahaba M, Diouf B, Cisse MM, Gueye S, Ka EF, et al. The burden of erectile dysfunction in dialysis patients in Senegal. Hemodial Int. 2011;15(2):280-3.

6. Nassir A. Erectile dysfunction risk factors for patients entering dialysis programme. Andrologia. 2010;42(1):41-7.

7. Rebollo P, Ortega F, Valdes C, Fernandez-Vega F, Ortega T, Garcia-Mendoza M, et al. Factors associated with erectile dysfunction in male kidney transplant recipients. Int J Impot Res. 2003; 15(6):433-8.

8. Messina LE, Claro JA, Archimedes N, Andrade E, Ortiz V, Srougi M. Erectile dysfunction in patients with chronic renal failure. Int braz JUrol. 2007;33(5):673-8.

9. Diemont WL, Hendriks JC, Lemmens WA, Langen $\mathrm{H}$, Berden $\mathrm{JH}$ Meuleman EJ. Prognostic factors for the vascular components of erectile dysfunction in patients on renal replacement therapy. Int J Impot Res. 2003;15(1):44-52.

10. Procci WR, Goldstein DA, Adelstein J, Massry SG. Sexual dysfunction in the male patient with uremia: a reappraisal. Kidney Int. 1981;19(2):317-23.

11. Malekmakan L, Shakeri S, Haghpanah S, Pakfetrat M, Sarvestani AS, Malekmakan A. Epidemiology of erectile dysfunction in hemodialysis patients using IIEF questionnaire. Saudi J Kidney Dis Transpl. 2011;22(2):232-6.

12. Rosas SE, Joffe M, Franklin E, Strom BL, Kotzker W, Brensinger C, et al. Prevalence and determinants of erectile dysfunction in hemodialysis patients. Kidney Int. 2001;59(6):2259-66.

13. Arslan D, Aslan G, Sifil A, Cavdar C, Celebi I, Gamsari T, et al. Sexual dysfunction in male patients on hemodialysis: assessment with the International Index of Erectile Function (IIEF). Int J Impot Res 2002;14(6):539-42.

14. Naya Y, Mizutani Y, Ochiai A, Soh J, Kawauchi A, Fujito A, et al. Preliminary report of association of chronic diseases and erectile dysfunction in middle-aged men in Japan. Urol. 2003;62(3):532-6.

15. Dailey DM. Understanding and affirming the sexual/relationship realities of end-stage renal disease patients and their significant others. Adv Ren Replace Ther. 1998;5(2):81-8.

16. Ayub W, Fletcher S. End-stage renal disease and erectile dysfunction. Is there any hope? Nephrol Dial Transplant. 2000;15(10):1525-8

17. Diao B. Erectile dysfunction in Senegal: Epidemiological Profile. Dakar; 1999.

18. Cerqueira J, Moraes M, Glina S. Erectile dysfunction: prevalence and associated variables in patients with chronic renal failure. Int J Impot Res. 2002;14(2):65-71.

19. Neto AF, de Freitas Rodrigues MA, Saraiva Fittipaldi JA, Moreira ED, Jr.. The epidemiology of erectile dysfunction and its correlates in men with chronic renal failure on hemodialysis in Londrina, southern Brazil. Int J Impot Res. 2002;14 Suppl 2:S19-26.

20. Droupy S. Epidemiology and pathophysiology of erectile dysfunction. Ann Urol. 2005;39(2):71-84.

21. Palmer BF. Sexual dysfunction in uremia. J Am Soc Nephrol. 1999; 10(6):1381-8.

22. Toorians AW, Janssen E, Laan E, Gooren LJ, Giltay EJ, Oe PL, et al Chronic renal failure and sexual functioning: clinical status versus objectively assessed sexual response. Nephrol Dial Transplant 1997;12(12):2654-63.

23. Kwan TH, Kit-Fan Lee M, Au TC. The impact of CAPD on sexual life of renal patients. Hong Kong Journal of Nephrology. 1999;1(1):41-8.

24. Miyata Y, Shindo K, Matsuya F, Noguchi M, Nishikido M, Koga S et al. Erectile dysfunction in hemodialysis patients with diabetes mellitus: association with age and hemoglobin A1c levels. Int $J$ Urol. 2004;11(7):530-4.

25. Phe V, Roupret M, Ferhi K, Barrou B, Cussenot O, Traxer O, et al [Erectile dysfunction and renal chronic insufficiency: etiology and management]. Prog Urol. 2009;19(1):1-7.

26. Fernandes GV, dos Santos RR, Soares W, de Lima LG, de Macedo BS, da Fonte JE, et al. The impact of erectile dysfunction on the quality of life of men undergoing hemodialysis and its association with depression. J Sex Med.2010;7(12):4003-10.

27. Kastrouni M, Sarantopoulou E, Aperis G, Alivanis P. Quality of life of Greek patients with end stage renal disease undergoing haemodialysis.J Ren Care. 2010;36(3):126-32. 